\title{
UN CASO DE RABDOMIOSARCOMA DEL UTERO
}

\author{
Doctores Eduardo Pérez Gómez y Luis Fernando Luzardo *
}

El Rabdomiosarcoma es un tumor, muy raro y sumamente maligno, de los músculos estriados (1).. Era muy poco conocido hasta la recopilación de Stout (2), quien encontró 323 casos descritos en sus diferentes localizaciones, lo cual indica su rareza. Se presenta con mayor frecuencia en etapas avanzadas de la vida especialmente entre la quinta y sexta décadas, con ligero predominio en varones. Se desarrolla de preferencia en ciertas regiones del cuerpo siendo las más comunes el sistema génito-urinario (vejiga, riñón, próstata, útero y vagina), y los músculos de las extremidades y del tronco; se han publicado casos de localización cardíaca. Las características clínicas varían según la localización y nos referimos más adelante a las que aparecen cuando el tumor se presenta en el útero. Las lesiones tienen un crecimiento muy rápido por lo cual experimentan con frecuencia procesos de necrosis y hemorragia, no siendo raro apreciar zonas de reblandecimiento quístico. El tumor puede ser único o multilobulado, circunscrito o difuso, e infiltrante; en ocasio-

* Del Departamento de Ginecología y Obstetricia. Hospital San Juan de Dios de Cúcuta. nes existe diseminación multicéntrica. La consistencia es variable y depende del contenido de colágeno; mientras algunas formaciones tumorales son firmes y elásticas, aquellas que han sufrido procesos de necrosis, hemorragia y liquefacción, son blandas. Desde el punto de vista microscópico el tumor es muy pleomórfico; su célula constituyente es variable habiendo descrito Stout 3 variedades o aspectos diferentes: redonda, alargada con 2 o 3 núcleos en serie, y en forma de raqueta, con un solo núc'eo en un extremo. Sinembargo las células pueden ser muy indiferenciadas y no guardar ninguna semejanza con células musculares primitivas o adultas. Robbins (1), describe además un tipo de células gigantes voluminosas, redondas u ovaladas, de citoplasma abundante lleno de vacuolas periféricas; las delgadas franjas de citoplasma que separan estas vacuolas les dan un aspecto característico, denominándose'as "células en telaraña"; Rakov en 1937 describió este mismo tipo celular en algunas de las formas más maduras del tumor. Las células suelen estar esparcidas en un fondo de elementos más indiferenciados y primitivos. El diagnóstico concluyente de Rabdomiosarcoma sólo lo da el hallaz- 
go de estriaciones cruzadas en las células neoplásicas, que se destacan especialmente con la coloración de ácido fosfotungstico y hematoxilina, aunque algunos patólogos sostienen que las características anotadas anteriormente son suficientes para hacer el diagnóstico. Sin embargo, la búsqueda paciente permite encontrar las células acintadas características muy similares a miocitos maduros con estriaciones cruzadas.

La malignidad de estos tumores es acentuada, y la supervivencia de 5 años es del orden del $3 \%$, produciéndose la muerte por diseminación hematógena y linfática a los ganglios regionales, huesos y pulmones. El tratamiento es quirúrgico radical y varía según la situación del tumor. Presentamos a continuación un caso de localización uterina de esta enfermedad.

Caso clínico. Historia clínica No 041705. A. O. 65 años de edad, natural de Villa del Rosario y procedente de Cúcuta. Ingresa al servicio de Ginecología del Hospital San Juan de Dios de Cúcuta el 17 de febrero de 1965 por presentar hemorragia vaginal profusa; sus síntomas se iniciaron 5 días atrás, cuando tras un episodio de dolor hipogástrico con irradiación dorsolumbar, apareció una descarga de líquido seroso por vagina, que luego se transformó en hemorragia franca abundante. Antes de estos hechos había permanecido asintomática. Sufrió de fiebre tifoidea a los 35 años y no ha sido operada. Su menarquia ocurrió a los 15 años y sus ciclos fueron regulares hasta hace 20 años cuando entró en menopausia. Nulípara y virgen. El único fa- miliar de la paciente, un hermano, padece carcinoma de la piel en la región palpebral derecha.

Al examen general se encontró paciente longilínea, delgada, en regulares condiciones generales. $\mathrm{P}=84 ; \mathrm{T}$. A. $=110 / 60$. Temp.: 3790 C.; palidez de los tegumentos, cataratas seniles, hipertrofia global del tiroides con algunos nódulos. Senos atróficos con pezones prominentes; al presionar la parte inferior del cuadrante ínfero-externo de la areola derecha aparece secreción sanguinolenta por el pezón. En el abdomen se palpó una masa dura, regular, móvil, de unos $10 \mathrm{cms}$. de diámetro en hipogastrio y cuadrante inferior derecho. La interconsulta cardiológica demostró los siguientes diagnósticos: arterioesclerosis generalizada, cardioesc!erosis, escleroenfisema pulmonar e insuficiencia venosa de los miembros inferiores. A la exploración ginecológica se apreciaron genitales externos atróficos, himen intacto rígido, vagina estrecha; a través del espéculo virginal, mucosa exocervical de aspecto normal; abundante metrorragia. Al tacto unidigital, conducto cervical dilatado por el cual salieron fragmentos de tejido necrótico en abun. dante cantidad y se pudieron tocar masas de tejido dentro de la cavidad de un útero agrandado, del tamaño aproximado de una gestación de 8 semanas. Los anexos eran normales y los parametrios libres. En una radiografía de tórax no se hallaron sombras de metástasis, pero sí enfisema y esclerosis. El examen histopatológico del tejido recogido reportó tejido necrótico y sombras de masas epiteliales. Los exámenes de laboratorio eran normales a excepción 
de anemia ( Hb 10 grs. y volumen globular 32). La prueba de Thorn evidenció escasa disminución de los eosinófilos circulantes, menor del $50 \%$. Se practicó biopsia del seno con el siguiente resultado: "Glándula mamaria con atrofia; no hay malignidad". No se realizó raspado biopsia por presentar fiebre persistente refractaria a los antibióticos, que nos indicó infección y necrosis endouterina, con posibilidad de diseminar la primera durante el raspado. Se hizo diagnóstico presuntivo de Adenocarcinoma de fondo uterino y después de preparar la paciente, se operó el 11 de marzo de 1965 realizándose histerectomía total con Salpingoooforectomía bilatera!. La paciente toleró bien el acto quirúrgico, el postoperatorio fue normal siendo dada de alta el 25 de marzo, con instrucciones para volver a controles periódicos. Un mes mas tarde fue vista en buenas condiciones. La paciente fallece el 11 de octubre con diseminación del tumor dentro de la cavidad abdominal (supervivencia, 7 meses).

El informe anatomopatológico es el siguiente:

Protocolo No M 2776. Pieza remitida: Utero y anexos.

Descripción macroscópica (fotografía 1). 1. Utero: mide $11 \times 6 \times 5 \mathrm{cms}$. Orificio cervical transversal; cavidad endometria! ocupada por una masa encefaloide, blanquecina, muy blanda, con zonas necróticas. El miometrio queda reducido a un espesor de $5 \mathrm{~mm}$. Se observa formación fibromatosa subserosa de $9 \mathrm{mms}$. 2. Ovario izquierdo: mide $2 \frac{1}{2} \times 1 \frac{1}{2} \times 0.4 \mathrm{cms}$. Superficie blan- quecina; al corte presenta nódulo necrótico blanquecino de $6 \mathrm{~mm}$. Trompa de Falopio; mide 6 x 0.5 cms.; presenta hidátide de Morgagni. 3. Ovario derecho: mide 2 x 0.7 cms. Color blanquecino; presenta un quiste de $2 \frac{1}{2}$ cms de diámetro, contenido seroso, pared translúcida. Trompa de Falopio mide $4 \times 0.5 \mathrm{cms}$.

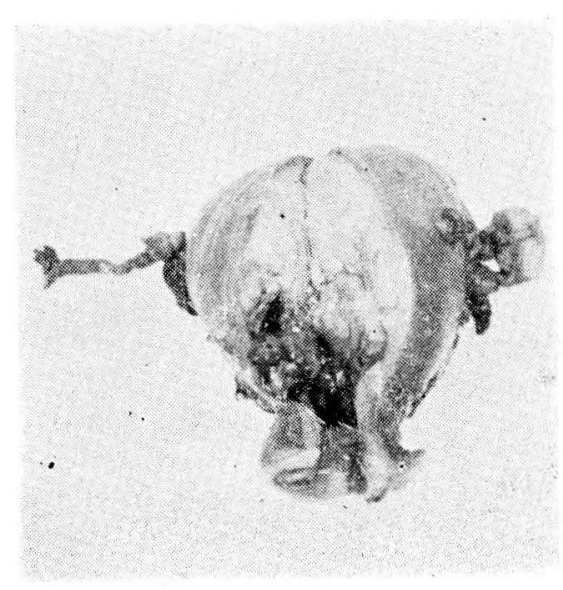

Figura 1

Descripción microscópica (microfotografías 2 y 3 ). Utero: en el endometrio se ha originado una tumoración maligna compuesta por células de variada morfología, gran número de ellas son alargadas, fusiformes, de citoplasmo eosinófilo; otras son piramidales o bizarras de abundante citoplasma y núcleo ovoide o esférico; quedan algunas glándulas cilíndricas de epitelio columnar parejo. Hay una clara limitación entre el miometrio y el tejido tumoral. Le hematoxilina férrica es positiva para estriaciones. Fibroma subseroso con cambio hialino; exocérvix con atrofia de su epitelio e infiltrado leucocitario 
en el estroma; dilatación quística endocervical.

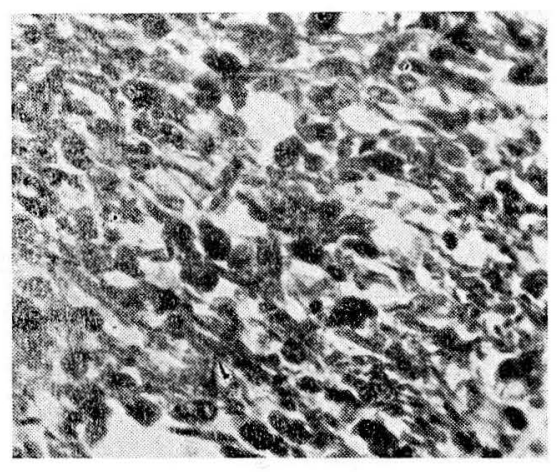

Figura 2

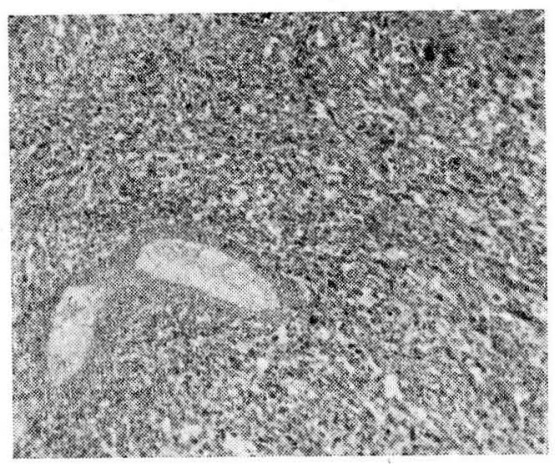

Figura 3

Diagnóstico: Sarcoma estromal del endometrio (rabdomiosarcoma). Ovario y trompas seniles. Cervicitis crónica. Fdo. Dr. G. Uribe Botero.

Comentario. Si consideramos la rareza del Sarcoma Uterino, que constituye a la luz de las estadísticas de Novak y Anderson (3), menos del 5\% de la totalidad de tumores uterinos malignos, vemos que la ocurrencia del rabdomiosarcoma es excepcional, toda vez que como se refirió anteriormente, sólo se han descrito 323 casos en la literatura mundial en todas sus localizaciones. Para catalogar este tumor hemos seguido la clasificación de Ober, por considerarla la más sencilla y clara. Corresponde a la forma de Sarcoma Mesenquimatoso de la variedad heteróloga pura. Las formas mesenquimales se originan en el endometrio y se denominan también, estromáticos endometriales o mesodérmicos mixtos (4); el denominador común de todas estas proliferaciones es el estroma del endometrio. Los sarcomas mesenquimales son poco frecuentes y el trabajo moderno de Taylor sugiere que existen menos de 150 casos ciertos en todo lo publicado hasta la fecha. Dentro de la clasificación propuesta por G. López Escobar y J. Mac Lean (5), el tumor encontrado en esta paciente correspondería a la forma de Sarcoma Endoexofítico del endometrio; para lo referente a la sintomatología de los sarcomas uterinos remitimos a los lectores a la excelente revisión de estos autores. Es de anotar que la gran mayoría de sarcomas uterinos pertenecen a la variedad de leiomiosarcoma. En el caso que presentamos hubiera podido llegarse al diagnóstico preoperatorio de haberse tenido más en cuenta las características físicas de la enferma y de haberse practicado un raspado biopsia, el cual no se efectuó por presentar algunos problemas técnicos y principalmente por temor a diseminar el proceso infeccioso endouterino manifestado por fiebre persistente que no respondió a la medicación. Se tuvo en consideración, que descartada la posibilidad de un carcino- 
ma de cérvix, el tratamiento debería ser quirúrgico radical sin linfadenectomía, y se procedió a intervenirla con diagnóstico clínico de Adenocarcinoma de endometrio. No por ello dejamos de considerar el raspado como paso obligado para el diagnóstico, cuando existen sospechas de enfermedad maligna del cuerpo uterino. La escasa supervivencia de esta paciente confirma la alta malignidad de esta forma tumoral. Algunos autores recomiendan la radioterapia complementaria postoperatoria como parte fundamental de la terapéutica; sin embargo la misma rareza de la neoplasia, no permite establecer bases estrictas para su tratamiento. Por el momento se recomienda el quirúrgico radical (histerectomía total $+\mathrm{S}$. O. bilateral).

\section{BIBLOGRAFIA}

1. ROBBINS: Patología. Ed. Interamericana. 2ạ Ed. Págs. 1.062-1063. 1963.

2. BLAIR S.: Tumores de huesos y músculos de las extremidas inferiores. Clin. Quir. de N. M. Ed. Interamericana. 257-8. Febrero de 1965.

3. NOVAK - SEEGAR: Tratado de Ginecología. Ed. Interamericana. 6a Ed., 356-366. 1962.

4. NOVAK y WOODRUFF: Ginecología y Obstetricia. Ed. Alhambra. 2a Ed., 238-249. 1964.

5. LOPEZ ESCOBAR G. y McLEAN J.: Sarcomas del Utero. Rev. Col. de Obst. y Gin. XI; 4: 339-375. 1960. 